\title{
Corrigendum: A question of scent: lavender aroma promotes interpersonal trust
}

\author{
Roberta Sellaro, Wilco W. van Dijk, Claudia Rossi Paccani, Bernhard Hommel and \\ Lorenza S. Colzato*
}

Cognitive Psychology Unit and Leiden Institute for Brain and Cognition, Leiden University, Leiden, Netherlands

Keywords: interpersonal trust, cognitive-control state, aromas, lavender, peppermint

\section{OPEN ACCESS}

Edited and reviewed by: Mariska Esther Kret, University of Amsterdam, Netherlands

${ }^{*}$ Correspondence: Lorenza S. Colzato colzato@fsw.leidenuniv.nl

Specialty section: This article was submitted to Cognition, a section of the journal Frontiers in Psychology

Received: 15 February 2015 Accepted: 17 February 2015 Published: 10 March 2015

Citation:

Sellaro R, van Dijk WW, Paccani CR Hommel B and Colzato LS (2015) Corrigendum: A question of scent: lavender aroma promotes interpersonal trust.

Front. Psychol. 6:243. doi: 10.3389/fpsyg.2015.00243

\section{A Corrigendum on}

A question of scent: lavender aroma promotes interpersonal trust by Sellaro, R., van DijK, W. W., Paccani, C. R., Hommel, B., and Colzato, L. S. (2015). Front. Psychol. 5:1486. doi: 10.3389/fpsyg.2014.01486

Mistakenly, the trust scores were reported in Euros, whereas the SD and CI were reported in Eurocents.

Please find below a list of corrections made to this article:

- On page 2, right column, under RESULTS-TRUST GAME, the first sentence should read "The dependent measure was the trust score, computed as the amount of money transferred to the trustee (in Eurocents), for each experimental group (Lavender, Peppermint, Control)."

- On page 3, left column, 7th row, the text " $M=3.90$ " should read " $M=390$."

- On page 3, left column, 8th row, the text " $M=3.23$ " should read " $M=323$."

- On page 3, left column, 9th row, the text " $M=3.20$ " should read " $M=320$."

Conflict of Interest Statement: The authors declare that the research was conducted in the absence of any commercial or financial relationships that could be construed as a potential conflict of interest.

Copyright $\odot 2015$ Sellaro, van Dijk, Paccani, Hommel and Colzato. This is an open-access article distributed under the terms of the Creative Commons Attribution License (CC BY). The use, distribution or reproduction in other forums is permitted, provided the original author(s) or licensor are credited and that the original publication in this journal is cited, in accordance with accepted academic practice. No use, distribution or reproduction is permitted which does not comply with these terms. 